\title{
KODA and its Analog Treatment Effects on Flowering and Spring Shoot Occurrence in Satsuma Mandarin
}

\author{
Naoko Nakajima ${ }^{4}$ \\ NARO Institute of Fruit Tree Science, Fujimoto, Tsukuba, Ibaraki 305-8605, \\ Japan
}

Yoshinori Ikoma ${ }^{1}$, Hikaru Matsumoto, and Keiko Sato

NARO Institute of Fruit Tree Science, Okitsu, Shimizu-ku, Shizuoka 4240292, Japan

Yuri Nakamura ${ }^{2}$
NARO Institute of Fruit Tree Science, Fujimoto, Tsukuba, Ibaraki 305-8605,
Japan

Mineyuki Yokoyama ${ }^{3}$ and Ohji Ifuku

Research Center, Shiseido Co. Ltd., Fukuura, Kanazawa-ku, Yokohama, Kanagawa 236-8643, Japan

\section{Shigeo Yoshida \\ Plant Science Center, RIKEN, Suehiro-cho, Tsurumi-ku, Yokohama, Kanagawa 230-0045, Japan}

Additional index words. 9-hydroxy-10-oxo-12(Z), 15(Z)-octadecadienoic acid, oxylipin, flower-bearing shoot, vegetative shoot, alternate bearing

\begin{abstract}
KODA [9-hydroxy-10-0xo-12(Z), 15(Z)-octadecadienoic acid] has previously been isolated from Lemna paucicostata, and is a compound known to promote flowering in plants. In this study, the effect of KODA on flower production and spring shoot occurrence in mature satsuma mandarin (Citrus unshiu Marc.) trees was examined in the field. The application of KODA in the summer or autumn had no discernible effect on flower production in the following year. However, when applied in summer, it promoted spring shoot occurrence in the following year, regardless of the number of flowers produced. In addition, C-KODA, a KODA analog, was more effective at producing this effect than KODA. The results suggest that the application of KODA or C-KODA may regulate spring shoot occurrence to improve the imbalance between the number of flower-bearing and vegetative shoots that leads to alternate bearing in satsuma mandarin trees.
\end{abstract}

A previous study reported that $\alpha$-ketol linolenic acid (KODA) was isolated from $L$. paucicostata as a stress-induced substance (Yokoyama et al., 2000). KODA is an oxylipin, a common compound in green plants (Vick and Zimmerman, 1987). Oxylipins are bioactive lipids produced by the oxidation of

Received for publication 28 Aug. 2015. Accepted for publication 3 Dec. 2015.

This work was supported by the Research and Development Program for New Bio-industry Initiatives, Japan.

${ }^{1}$ Present address: NARO Institute of Fruit Tree Science, Fujimoto, Tsukuba, Ibaraki 305-8605, Japan.

${ }^{2}$ Present address: National Agriculture and Food Research Organization, Headquarters, Kannondai, Tsukuba, Ibaraki 305-8517, Japan.

${ }^{3}$ Present address: Kihara Institute for Biological Research, Yokohama City University, Maioka-cho, Totsuka-ku, Yokohama, Kanagawa 244-0813, Japan.

${ }^{4}$ Corresponding author. E-mail: nnaoko@affrc. go.jp. polyunsaturated fatty acids (Lee et al., 2008). It was shown that KODA is related to flower induction in L. paucicostata and Pharbitis nil (Suzuki et al., 2003; Yokoyama et al., 2000). Among fruit trees, endogenous KODA might be associated with flower bud formation in apple trees (Kittikorn et al., 2010), as the application of exogenous KODA promotes flower bud formation by decreasing the expression of MdTFL1 (Kittikorn et al., 2011). Therefore, KODA may also be related to flower formation in fruit trees. Besides, KODA was recently reported to have some effects (with the exception of flowering) on fruit trees. For example, KODA was shown to influence ethylene production by apple fruits (Kondo et al., 2012). Furthermore, Sakamoto et al. (2012) indicated that the application of KODA tended to accelerate bud differentiation and development in Japanese pears.

Many fruit trees alternate between years of high yield and years of poor yield, a phenomenon called alternate bearing. It is one of the most severe and widespread problems affecting commercial fruit production. In citrus, the prevention of alternate bearing has been the subject of many studies, which evaluated the preventative capabilities of girding, pruning, or fruit thinning. However, the definitive method of preventing alternate bearing has not yet been developed. In Japan, alternate bearing in satsuma mandarin trees is a serious problem even today. Thus, the development of a method of stabilizing flower setting for satsuma mandarin trees is needed to prevent their alternate bearing.

In citrus, flowering is induced by the accumulation of chilling hours under floralinductive conditions (temperatures lower than $\approx 25{ }^{\circ} \mathrm{C}$ ) during the autumn and winter (Inoue, 1990). In our previous study, we examined the effect of exogenous KODA application on flower bearing in 1-year-old satsuma mandarin trees (Nakajima et al., 2011), and demonstrated that KODA application under floral-inductive conditions can promote flower bearing when the number of chilling hours accumulated has been insufficient to induce flowering. In the present study, KODA was applied in either summer or autumn, either before or under flowerinductive conditions, to examine the effects of KODA application on flower bearing and spring shoot under different chilling hours. Moreover, we discussed whether KODA application stabilize flower setting and thus prevent alternate bearing in mature satsuma mandarin trees.

\section{Materials and Methods}

Chemicals. KODA was prepared as described previously (Kittikorn et al., 2010). C-KODA is an analog of KODA (Fig. 1) that is formed by introducing a chlorine atom and a hydroxyl group at the C-15 olefin of KODA as follows (Kondo et al., 2012): $250 \mathrm{~mL}$ KODA (32 mM) was mixed with $690 \mathrm{~mL}$ pure water, followed by the addition of $60 \mathrm{~mL}$ dilute aqueous solution $[10 \%$ of sodium hypochlorite solution on the market (active chlorine $8.5 \%$ to $13.5 \%$, Nakalai Tesque, Inc, Kyoto, Japan)] while mixing vigorously. C-KODA was extracted using ethyl acetate, and isolated with high-performance liquid chromatography (NANOSPACE SI-1, Shiseido, Tokyo, Japan) using a CAPCELL PAK $\mathrm{C}_{18}$ column (Shiseido). The mobile phase was $50 \%$ $\mathrm{CH}_{3} \mathrm{CN}$ in $0.05 \%$ trifluoroacetic acid.

Plant material. Experiment 1 was conducted using 15-year-old satsuma mandarin trees (C. unshiu Marc, 'Nichinan-ichigou') grafted onto trifoliate orange rootstocks in an open field at the NARO Institute of Fruit Tree science, National Agricultural Research Organization, (Okitsu, Shizuoka, Japan). Experiment 2 used 16-year-old satsuma mandarin trees ('Nichinan-ichigou') grown in the same manner as those in Experiment 1.

Experiment 1: Effects of KODA treatment in the summer or autumn on the number of flowers and spring shoots. Three 15-year-old trees were randomly selected. In summer (29 July), a primary scaffold branch of each 
tree was sprayed with $100 \mu \mathrm{M}$ KODA solution containing $0.1 \%$ Tween 20 and $0.6 \%$ ethanol. Meanwhile, another primary scaffold branch of the tree was sprayed with $0.1 \%$ Tween 20 and $0.6 \%$ ethanol solution (control branch). The crop load of all trees had already been decreased by fruit thinning to an approximate leaf:fruit ratio of 20 in late June. Additionally, after harvesting in autumn (10 Oct.), another three trees were treated with KODA using the same methods used in the summer. In the next spring, the number of flowers (containing two types of inflorescence: leafless inflorescences and inflorescences with leaves), spring shoots, and old leaves in each treatment was counted.

Experiment 2: Effects of summer KODA and C-KODA treatment on the number of flowers, spring shoots, and fruits dropped. In the year after Experiment 1, three 16-yearold trees not used in Experiment 1 were randomly selected. In the summer (4 Aug.), a primary scaffold branch of each tree was sprayed with $100 \mu \mathrm{M}$ KODA solution containing $0.1 \%$ Tween 20 and $0.6 \%$ ethanol. Another primary scaffold branch was sprayed with $100 \mu \mathrm{M}$ C-KODA solution containing $0.1 \%$ Tween 20 and $0.6 \%$ ethanol. In addition, a control branch in each tree was treated with a $0.1 \%$ Tween 20 and $0.6 \%$ ethanol solution. The crop loads of all trees had already been decreased by fruit thinning to an approximate leaf:fruit ratio of 20 in late June. In the next spring, on 10 May, the number of flowers (containing two type of inflorescence: leafless inflorescences and inflorescences with leaves), spring shoots, and old leaves in each treatment was counted. Additionally, the number of only inflorescences with leaves was counted. On 3 June, new leaves and old leaves in each treatment were counted to calculate the number of new leaves produced per old leaf. After physiological fruit drop, on 15 July, the number of leaves and the number of fruits remaining on each treated branch were counted, and the number of leaves per fruit and the ratio of dropped fruits to flowers were calculated for each branch.

\section{Results}

Experiment 1: Effects of KODA treatment in summer or autumn on the number of flowers and spring shoots. To study the effects of KODA treatment on flower and spring shoot production in the satsuma mandarin, we investigated the number of flowers and spring shoots in the next spring of KODA application year. On branches sprayed with KODA solution in the summer, there was no difference between the number of flowers relative to old leaves on treated and control branches (Fig. 2A), but the number of spring shoots relative to old leaves increased significantly (Fig. 2B). The ratio of flowers to spring shoot was decreased significantly by the application of a KODA treatment in the summer (Fig. 2C). Conversely, on branches sprayed with KODA solution in the autumn, there was no difference between the number of flowers produced relative to old leaves on treated and control branches (Fig. 2D). However, in this case, the number of spring shoots relative to old leaves and the ratio of flowers to spring shoot in the treatment groups did not differ from those of control branches (Fig. 2E and F).

Experiment 2: Effects of KODA and $C-K O D A$ treatment in the summer on the number of flowers and spring shoots produced. To confirm the effects of the KODA treatment observed in Experiment 1 and study the effects of C-KODA treatment, satsuma mandarin trees were treated with either KODA or C-KODA in the summer (4 Aug.) after Experiment 1. The number of flowers produced relative to old leaves on the branches treated with KODA did not differ from that of control branches (Fig. 3A), as was observed in Experiment 1. Additionally, the number of only inflorescences with leaves relative to old leaves on the branches treated
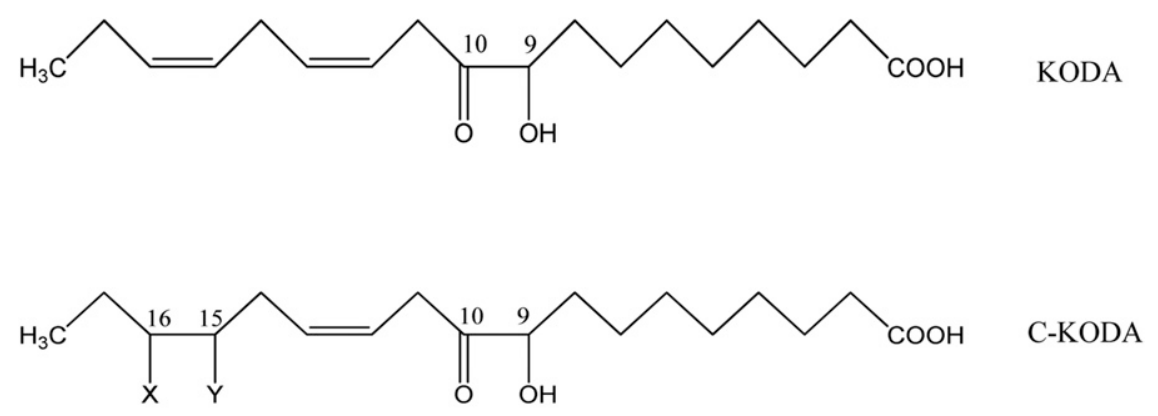

$$
\begin{aligned}
& \mathrm{X}=\mathrm{Cl}, \mathrm{Y}=\mathrm{OH} \\
& \text { or } \\
& \mathrm{X}=\mathrm{OH}, \mathrm{Y}=\mathrm{Cl}
\end{aligned}
$$

Fig. 1. The structure of KODA and C-KODA, an analog of KODA.

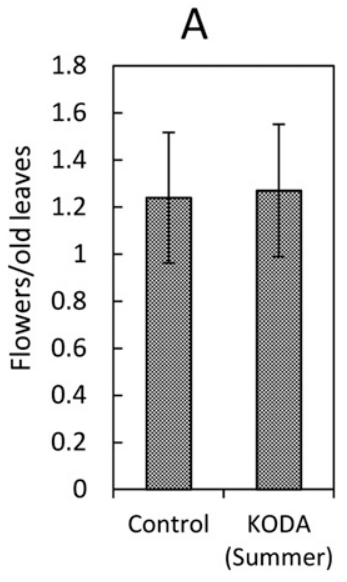

D

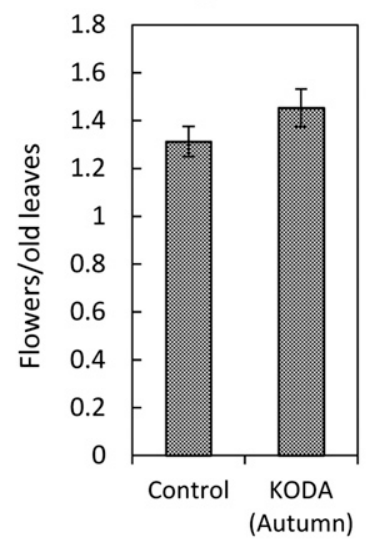

B

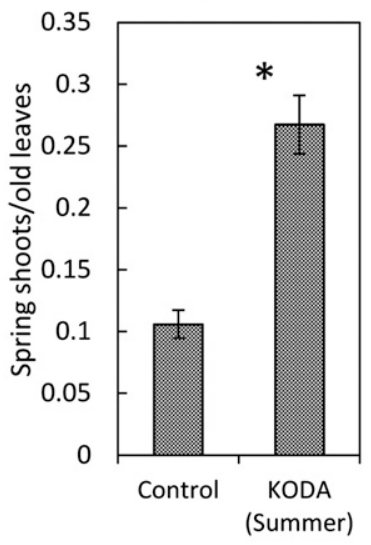

$\mathrm{E}$

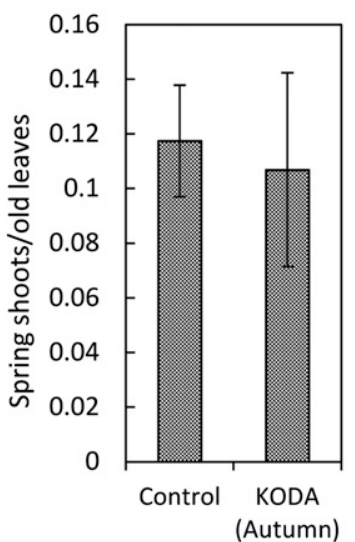

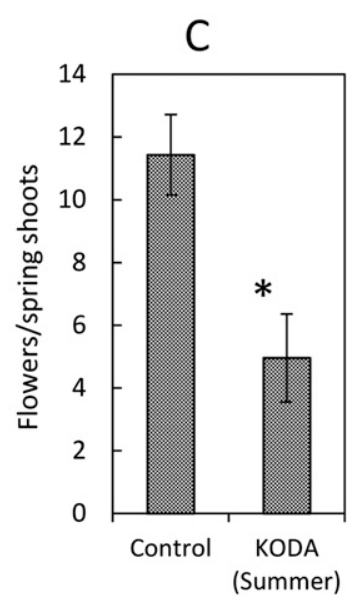

$\mathrm{F}$

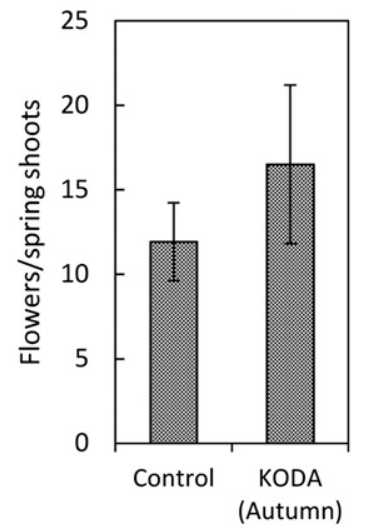

Fig. 2. Effects of KODA treatment on (A, D) the number of flowers produced relative to the number of old leaves, $(\mathbf{B}, \mathbf{E})$ the number of spring shoots produced relative to the number of old leaves, and $(\mathbf{C}, \mathbf{F})$ the number of flowers produced per spring shoot. $\mathbf{A}-\mathbf{C}$ are the results of applying the treatment in the summer (29 July) and D-F are results of applying the treatment in the autumn (10 Oct.). Vertical bars represent SE $(\mathrm{n}=3)$. *Significant difference at the $5 \%$ level according to Student's $t$-test. 
with KODA did not differ significantly from that of control branches (data not shown). The same was true of branches treated with C-KODA (Fig. 3A). The number of spring shoots relative to the number of old leaves on C-KODA treated branches was significantly higher than that of the control (Fig. 3B). The same was generally true for KODA treated branches, but unlike in Experiment 1, the difference was not significant (Fig. 3B). Conversely, the ratio of flowers to spring shoot tended to decrease compared with the control on branches treated with KODA or C-KODA. The difference was especially significant between the C-KODA treatment and the control (Fig. 3C). Moreover, the C-KODA treatment significantly increased the number of new leaves produced relative to old leaves (Fig. 4A). The KODA treatment also tended to increase that number, but the difference was not significant (Fig. 4A). After physiological fruit drop, neither KODA nor CKODA treatment was observed to influence either the number of leaves per fruit (Fig. 4B) or the number of dropped fruits per flower (Fig. 4C).

\section{Discussion}

In this study, the application of KODA and C-KODA had a significant effect on spring shoot occurrence. In our previous study, the effect of exogenous KODA application on the flower bearing of 1-year-old satsuma mandarin (C. unshiu Marc.) trees was examined (Nakajima et al., 2011), and it was shown that KODA treatment under floral-inductive conditions could promote flower bearing when the number of chilling hours accumulated was insufficient to induce flowering. However, it was suggested that the principal cause of the increase in flower bearing due to KODA was the promotion of axillary bud sprouting. After all, KODA treatment in the autumn (under floralinductive conditions) promoted the sprouting of both flower and shoot buds, thus seeming to promote flower bearing in the satsuma mandarin. In this study, the application of KODA treatment in the summer promoted the occurrence of spring shoots, but autumn application was not similarly effective. This may be because of differences between the mature trees used in this study and the 1-yearold trees in the early stages of the floralinductive process used in the previous study. In the 1-year-old trees, flower bearing and spring shoot occurrence were not influenced by the fruit load of the previous year. Conversely, in the mature trees, flower bearing and spring shoot occurrence were significantly influenced by the previous year's fruit load. Therefore, the application of KODA to the mature trees interacted with factors such as the previous year's fruit setting, and thus differed from the effects of the treatment on 1 -year-old trees.

In citrus, the harvest can be manipulated to reduce the number of flowers and the amount of fruit produced in the following year. Flower-bearing shoots produce only vegetative shoots in the following spring. Meanwhile, vegetative shoots will produce flowers in the following spring. Therefore, in citrus, alternate bearing is caused by the numerical imbalance of flower-bearing shoots and vegetative shoots. In Experiment 2, the effect of KODA on spring shoot occurrence, which was higher (but not significantly so) in this treatment than in the control, was not as significant as that observed in Experiment 1 (Fig. 3B). The reasons for this are speculated to be as follows: in Experiment 1, the application of KODA was carried out during a poor crop year, and in the next year (a rich crop year), the number of spring shoots produced by the control branches was comparatively lower. Thus, KODA treatment should be more effective than has been supposed. On the contrary, in Experiment 2, the application was carried out during a rich crop year, and in the next year (a poor crop year), the number of spring shoots in the control was relatively large. Thus, the effect of KODA application is unclear, as this
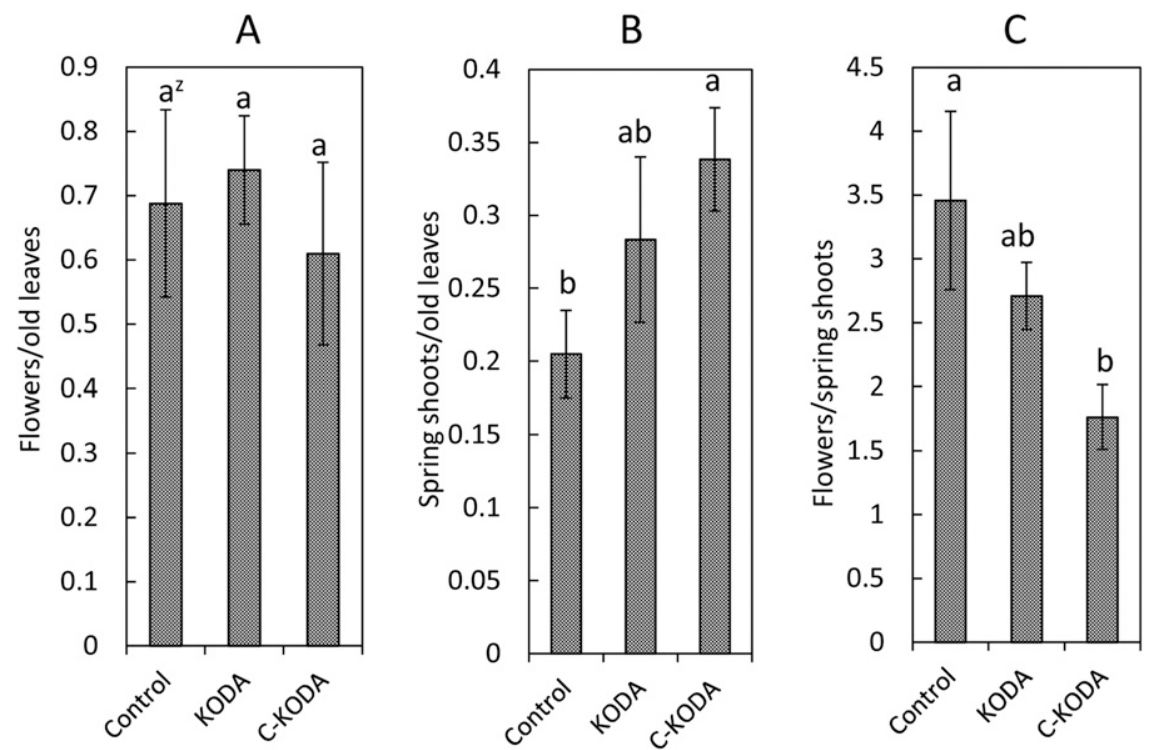

Fig. 3. Effects of KODA or C-KODA treatment applied in the summer (4 Aug.) on (A) the number of flowers produced relative to the number of old leaves, $(\mathbf{B})$ the number of spring shoots produced relative to the number of old leaves, and $(\mathbf{C})$ the number of flowers per spring shoot. Vertical bars represent SE $(n=3) .{ }^{2}$ Different letters indicate significant differences at the $5 \%$ level according to the Tukey-Kramer honestly significant difference test.

A

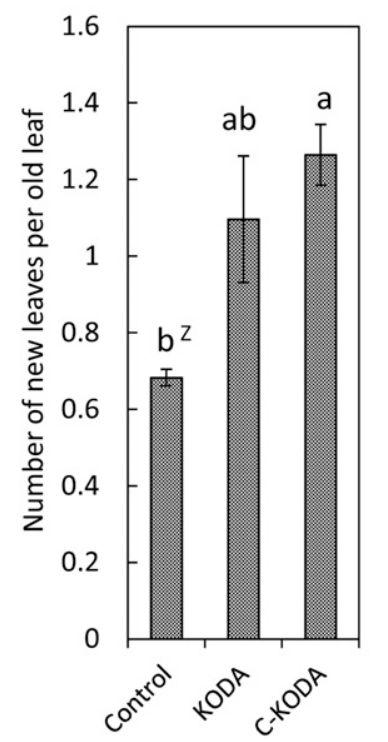

B

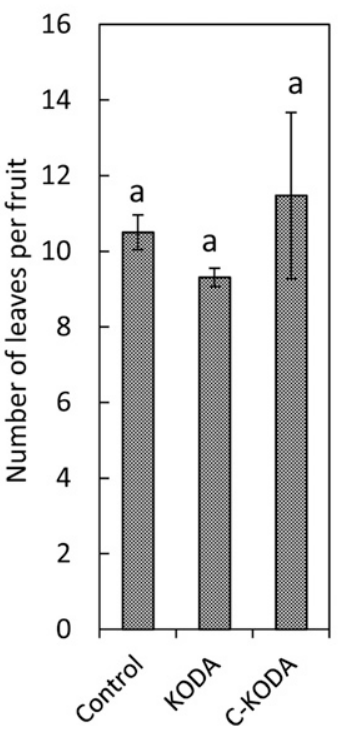

C

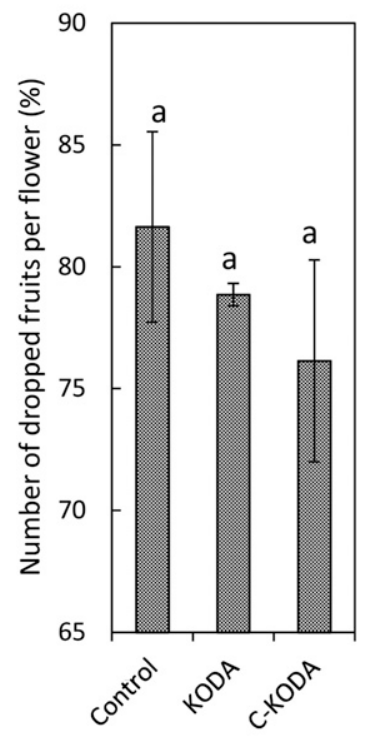

Fig. 4. Effects of KODA or C-KODA treatment applied in the summer (4 Aug.) on (A) the number of new leaves relative to the number of old leaves, $(\mathbf{B})$ the number of leaves per fruit, and $(\mathbf{C})$ the number of

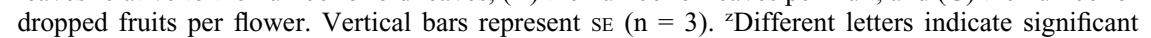
differences at the $5 \%$ level according to the Tukey-Kramer honestly significant difference test. 
implies that the effect of KODA on spring shoot occurrence in Experiment 2 was not as significant as that observed in Experiment 1.

If we increase the number of the vegetative shoots in spring of rich crop year, it can increase the number of flower in the following year (a poor crop year). Treated with KODA or C-KODA in summer of poor crop year, the number of vegetative shoots produced during the following rich crop year can be increased, while keeping the number of flowers consistent. This prevents a decrease in the number of flowers produced in the following year (a poor crop year) and corrects the imbalance between the numbers of flower-bearing and vegetative shoots produced to better balance alternate bearing. Therefore, the application of KODA or C-KODA is considered to be a viable method of alleviating the negative impacts of alternate bearing in satsuma mandarin trees.

It has been established that in citrus, flowering is inhibited by the application of exogenous gibberellic acid (Guardiola et al., 1982), and that levels of endogenous gibberellins are speculated to influence flower induction (Takagi et al., 1989). Therefore, to promote flower setting, the application of gibberellin biosynthesis inhibitors has been investigated. The application of the compounds enhanced flower setting, but the occurrence of spring shoots tended to be inhibited (Ogata et al., 1995), decreasing flower setting in the next year. Conversely, the application of KODA or CKODA enhanced spring shoot occurrence, and did not affect the number of flowers produced relative to the number of old leaves (Fig. 3A), the number of leaves per fruit (Fig. 4B), or the number of dropped fruits per flower after physiological fruit drop (Fig. 4C). Additionally, C-KODA treatment is seemed to be more effective at promoting the occurrence of spring shoots than KODA treatment. This is speculated to be because of the instability of KODA, which is likely to break down after application (Kai et al., 2007). C-KODA, an analogue of KODA, was produced to solve the problem of KODA instability.

Furthermore, in this study, it was demonstrated that KODA or C-KODA treatment in the summer increased the number of spring shoots produced in the following year, without affecting the number of flowers produced. In addition, application of C-KODA, an analogue of KODA, was more effective than the application of KODA itself. Therefore, treatment with KODA or C-KODA in the summer of a poor crop year can prevent decreases in the number of spring shoots produced during rich crop years to increase the number of flowers produced during poor crop years. Thus, it is possible to resolve the problem of alternate bearing in satsuma mandarin trees and stabilization the rate of production. However, this result was unprecedented and the mechanism behind it remains unknown. In future studies, this mechanism will be elucidated to facilitate the use of KODA and C-KODA to regulate spring shoot occurrence in satsuma mandarin trees. Recently, Sakamoto et al. (2010) demonstrated that the application of KODA to japanese pear trees during the endodormancy stage could effectively promote the breaking of flower buds. In addition, it has been shown that KODA applications to apple fruit influence ethylene production (Kondo et al., 2012). Therefore, it is speculated that KODA exhibits a wide range of bioactivity unrelated to flowering, the effects of KODA application on the spring shoots of mature satsuma mandarin trees being among them.

\section{Literature Cited}

Guardiola, J.L., C. Monerri, and M. Agusti. 1982. The inhibitory effect of gibberellin acid on flowering in Citrus. Physiol. Plant. 55:136142.

Inoue, H. 1990. Effect of temperature on bud dormancy and flower bud differentiation in Satsuma mandarin. J. Jpn. Soc. Hort. Sci. 58:919-926. (in Japanese with English summary).

Kai, K., F. Yano, F. Suzuki, H. Kitagawa, M. Suzuki, M. Yokoyama, and N. Watanabe. 2007. Metabolism of $\alpha$-ketol derivative of linoleic acid (KODA), a flowering-related compound, in Pharbitis nil. Tetrahedron 63:10630-10636.

Kittikorn, M., N. Shiraishi, K. Okawa, H. Ohara, M. Yokoyama, O. Ifuku, S. Yoshida, and S. Kondo. 2010. Effect of fruit load on 9, 10-ketol-octadecadienic acid (KODA), GA and jasmonic acid concentrations in apple buds. Sci. Hort. 124:225-230.

Kittikorn, M., K. Okawa, H. Ohara, N. Kotoda, M. Wada, M. Yokoyama, O. Ifuku, S. Yoshida, and S. Kondo. 2011. Effects of fruit load, shading, and 9, 10-ketol-octadecadienic acid (KODA) application on MdTFL1 and MdFTlgenes in apple buds. Plant Growth Regulat. 64:75-81.

Kondo, S., H. Tomiyama, M. Kittikorn, K. Okawa, H. Ohara, M. Yokoyama, O. Ifuku, T. Saito,
Y. Ban, M. Tatsuki, T. Moriguchi, A. Murata, and N. Watanabe. 2012. Ethylene production and 1-aminocyclopropane-1-carboxylate (ACC) synthase and ACC oxidase gene expression in apple fruit are affected by 9, 10ketol-octadecadienoic acid (KODA). Postharvest Biol. Technol. 72:20-26.

Lee, D.S., P. Nioche, M. Hamberg, and C.S. Raman. 2008. Structural insights into the evolutionary paths of oxylipin biosynthetic enzymes. Nature 455:363-368.

Nakajima, N., Y. Ikoma, H. Matsumoto, Y. Nakamura, M. Yokoyama, O. Ifuku, and S. Yoshida. 2011. Effect of 9, 10- $\alpha$-ketol linolenic acid treatment on flower bearing in satsuma mandarin. Hort. Res. (Japan) 10:407-411. (in Japanese with English summary)

Ogata, T., Y. Ueda, S. Shiozaki, S. Horiuchi, and K. Kawase. 1995. Effects of gibberellin synthesis inhibitors on flower setting of satsuma mandarin. J. Jpn. Soc. Hort. Sci. 64:251-259. (in Japanese with English summary).

Sakamoto, D., Y. Nakamura, H. Sugiura, T. Sugiura, T. Asakura, M. Yokoyama, and T. Moriguchi. 2010. Effect of 9-hydoroxy-10oxo-12(Z), 15(Z)-octadecadienoic acid (KODA) on endodormancy breaking in flower buds of Japanese pear. HortScience 45:1470 1474.

Sakamoto, D., Y. Nakamura, M. Yokoyama, O Ifuku, and T. Moriguchi. 2012. Effect of 9-hydoroxy-10-oxo-12(Z), 15(Z)-octadecadienoic acid (KODA) on lateral primordial formation in the apical flower buds of Japanese pear [Pyrus pyrifolia (Burm.f.) Nakai]. Sci. Hort. 140:33-38.

Suzuki, M., S. Yamaguchi, T. Iida, I. Hashimoto, H. Teranishi, M. Mizoguchi, F. Yano, Y Todoroki, N. Watanabe, and M. Yokoyama. 2003. Endogenous $\alpha$-ketol linolenic acid levels in short day-induced cotyledons are closely related to flower induction in Pharbitis nil. Plant Cell Physiol. 44:35-43.

Takagi, T., A. Tomiyasu, M. Matsushima, and T. Suzuki. 1989. Seasonal changes of GAlike substances in fruit and current shoots of satsuma mandarin trees. J. Jpn. Soc. Hort. Sci. 58:569-573. (in Japanese with English summary).

Vick, B.A. and D.C. Zimmerman. 1987. Oxidative system for modification of fatty acid: The lipoxygenase pathway, p. 53-90. In: P.K. Stumpf and E.E. Conn (eds.). The biochemistry of plants, a comprehensive treatise. Vol. 9. Academic Press, New York, NY.

Yokoyama, M., S. Yamaguchi, S. Inomata, K. Komatsu, S. Yoshida, T. Iida, Y. Yokokawa, M. Yamaguchi, S. Kaihara, and A. Takimoto. 2000. Stress-induced factor involved in $\alpha$-ketol derivative of linolenic acid. Plant Cell Physiol. 41:110-113. 